\title{
Oktay BELLI, Kırgızistan'da Taş Balbal ve Insan Biçimli Heykeller Stone Balbals and Statues in Human Form in Kirghizistan, Arkeoloji ve Sanat Yayinlar, İstanbul, 2003, VIII+166 s.
}

Dr. Osman MERT*

\begin{abstract}
ÖZET
"Kırgızistan'da Taş Balbal ve Insan Biçimli Heykeller Stone Balbals and Statues in Human Form in Kirghizistan, Arkeoloji ve Sanat Yayınları, İstanbul, 2003" adlı eser, Prof. Dr. Oktay BELL! ve ekibinin Avrasya Arkeoloji Projesi kapsaminda 04-26 Eylu! 2001 tarihleri arasında Kırgızistan Cumhuriyeti'nin ceșitli bolgelerinde gerçekleştirmiş olduğu çalışmaları ihtiva etmektedir.

Avrasya Arkeoloji Projesi ekibi tarafindan yapılan yüzey araştırmaları sayesinde Eski Türk kültür ve medeniyetine ait birçoğu literatürde yer almayan, Kırgızistan coğrafyasının cetin şartlarına direnerek günümüze ulaşmayı başaran taşbabalar, heykeller, balballar, kurganlar, mezarlar ve mezar külliyeleri ortaya çıarılmıs ve bu eser vasitasılyla da ilgilenenlerin istifadesine sunulmuştur.
\end{abstract}

7. 7 . 3. W. Cumhuriyeti toprakları bugün de Türk tarihinin eşsiz kültür ve medeniyet eserlerini uzerinde barındırmaktadır. Kırgızistan Cumhuriyeti her ne kadar cografî olarak ủlkemizden uzakta bulunsa da bugün sosyal, siyasî ve kültürel ilişkilerimizi geliştirmek istediğimiz ulkelerin önde gelenlerindendir. Hem söz konusu ilişkileri hem de Kırgız Türkleri'yle olan tarihî, baglarımızı canlandırmak, guçlendirmek amacıyla İstanbul Üniversitesi Rektörlŭğ ile Kırgızistan - Türkiye Manas Ưniversitesi Rektörluğ arasında bilimsel işbirligi antlaşmaları imzalanmış ve İstanbul Üniversitesi'nin destekledigi Avrasya Arkeoloji Projesi geliştirilerek uygulamaya konulmuștur ${ }^{\text {l. }}$.

Başkanlığını Prof. Dr. Oktay BELLI'nin yurutttuğ İstanbul Üniversitesi Avrasya Arkeoloji Projesi'nde Dr. Orhan DOGAN (Kazakistan Tarihi Uzmanı), Okutman Erkan KONYAR (Demirçag Uzmanı), Araş. Gör. Can AVCI (Demirçą̆ Uzmanı), Araş. Gör. Ibrahim ÇEŞMELI (Turk Sanatı Tarihi Uzmanı), Araş. Gör.

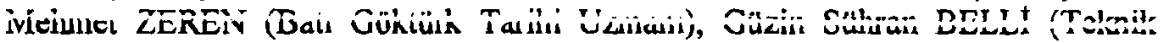

* Ataturk Universitesi Kâzım Karabekir Eğitim Fakültesi Ögretim Óyesi

'Proje hakkında bilgi için bk. BELLI, Oktay, Kırgızistan'da Taş Balbal ve İnsan Biçimli Heykeller Stone Balbals and Statues in Human Form in Kirghizistan, Arkeoloji ve Sanat Yayınları, İstanbul, 2003, s. VII-VIII. 
Ressam) ve Kırgızistan - Turkiye Manas Üniversitesi Tarih Bolumu'nden Asılbek COONDONBEKOV gorev almışlardır.

Kırgizistan'da Taş Balbal ve Insan Biçimli Heykeller Stone Balbals and Statues in Human Form in Kirghizistan adli eser, Prof. Dr. Oktay BELLI ve ekibinin Avrasya Arkeoloji Projesi kapsamında 04-26 Eylul 2001 tarihleri arasında Kırgızistan Cumhuriyeti'nin Bişkek, Burana, Koçkor, Issık Kol bőlgelerinde (muze ve yerleşim alanları dahil olmak uzere) yapılan yuzey araştırmalarının bir kısmının sonuçlanının ürunudür. Avrasya Arkeoloji Projesi ekibi tarafindan yapılan yüzey araştırmaları sayesinde Eski Türk kultur ve medeniyetine ait birçoğu literaturde yer almayan, Kırgızistan cografyasının çetin şartlarına direnerek günumtize ulaşmayı başaran taşbabalar, heykeller, balballar, kurganlar, mezarlar ve mezar kulliyeleri ortaya çkarılmıs ve bu eser vasıtasıyla da ilgilenenlerin istifadesine sunulmuştur. Kapsamlı olarak gerçekleştirilen bu çalışmada Kırgızistan'daki arkeolojik araştırmaların onemli bir bölümünün taş heykel ve balballara ayrılarak taş heykel ve balbalların, Türkler'de olu gömme gelenekleriyle birlikte değerlendirildiği görulmektedir.

Arkeoloji ve Sanat Yayınları tarafından yayımlanan ve Kırgızistan'da 19. yuzyılın ikinci yarısından gunumüze kadar yapılan arkeolojik kazılar hakkında da ayrıntılı bilgiler içeren eserde, yerli ve yabancı bilim adamlarının yararlanabilmesi için V. ve VI. bölumlerdeki bilgilerin İngilizcesine de yer verilmiştir. Eserde yer alan kurganlar, taş heykeller ve söz konusu kültür ve medeniyet eserleri hakkındaki bilgiler çizim ve fotograflarla da desteklenmiștir.

Kitabın ơn kapağında sağ eliyle goğüs hizasında kadehte bengisu, sol eliyle de kılıcını tutan bir taşbaba bulunmaktadır. Kitabın arka kapağında ise şu bilgilere yer verilmiştir: "Karadeniz'in kuzeyindeki bozkırlardan Mogolistan topraklarının sonuna değin uzanan geniş coğrafí bölgede, binlerce insan biçimli taş heykel ve balbal bulunmaktadır. Insan biçimli taş heykel ve balballar, 6.-13. yüzyıllar arasında Türk toplulukları tarafindan oldukça yaygın olarak kült merkezlerinin çevresine ve kurganlarm üzerine dikilmiştir. Taş heykeller balballara kyasla olduķ̧a özenli ve gerçekci bir biçimde işlenmişlerdir. Heykellerin özenli ve ayrıntıll olarak işlenmesinin özünde, ölen kişinin varlığının elle tutulur bir biçimde sürdürülmesi düşüncesi gelmektedir. Bu yüzden taștan yaplan insan heykelleri, Tük tarihinde "Ata Kültü"nü tüm canlılı̆̆ ile yansıtmaktadır. Insan heykellerinin yanı sıra, başında ü̧̧en çıkıntılı bir tą̧ taşıyan Umay Ana heykelleri, doğurganlık, üretkenlik ve koruyuculuğun bir simgesi olarak karşımıza çıkmaktadır. Günümüzde bile Türk toplulukları taştan yapılan insan heykellerini kutsal kabul etmekte ve bunlarl "taşnine" olarak adlandırmaktadır. Eski inancl sürdüren Türk topluluklarl insan biçimli tas heykel ve balballara dualar etmekte, adaklar adamakta, taşlarl kucaklamakta, saygigla opmekte ve isteklerinin olumlu yönde sonuçlanması için bezler bağlamaktadır." 
"Kırgızistan'da Taş Balbal ve Insan Biçimli Heykeller Stone Balbals and Statues in Human Form in Kirghizistan" adlı eserde sırasıyla: Içindekiler/Contents (V), Sunuş (VII), Giris (1-4), Kırgızların Tarihine Genel Bir Bakış (5-9), Kurgızistan'da Yapılan Arkeolojik Araştırmaların Tarihçesi (10-11), Türklerde Ölü Gömme Gelenekleri (Kurganlar, Kurbanlar, Şölenler, Armaganlar) (12-34), Kırgızistan'da Taş Balbal ve Insan Biçimli Heykeller (Taş Balballar, Insan Biçimli Taş Heykeller, Umay Ana Heykelleri, Insan Biçimli Taş Heykellerin Kutsallığı, Sonuç) (35-50), Kurgızistanda Taş Balbal ve Insan Biçimli Heykellerin Tipolojik Incelenmesi (Taş Balballar, Insan Biçimli Taş Heykeller (Erkek Heykelleri, Umay Ana Heykelleri)) (51-103), Stone Statues and Balbals in Kirghizistan (Turkic Burial Traditions, Kurgans, Offerings Feasts, Gifts, Stone Balbals and Statues in Human Form In Kirghizistan (Stone Balbals, Stone Statues in Human Form, Statues of Mother Umay, Holiness of the Statues in Human Form, Conclision)) (104-135), Dizin, Indeks, Kaynakça - Bibliyography (Kaynak ve Seyahatname]er-Sources and Expedition Reports, Modern Araştırmalar- Modern Researches) (136-166) yer almaktadır.

Türk tarihi, Turk kulturu ve medeniyeti sahalarında şimdiye kadar hazırlanmiş en ciddî ve en onemli başvuru eserlerinden biri olan "Kırgızistan'da Taş Balbal ve Insan Biçimli Heykeller Stone Balbals and Statues in Human Form in Kirghizistan" adlı eser, hem bundan sonra yaplacak benzeri çalişmalara pek ̧ok açıdan kaynak teşkil edecek, hem de Kırgızistar'da günümuze ulaşabilen ata yadigârı taşbabaların, taş balbalların gelecek nesillere tanıtımında Eilył̧ bir boşluğa dolduracaktır.

"Kırgızistan'da Taş Balbal ve Insan Biçimli Heykeller Stone Balbals and Statues in Human Form in Kirghizistan" adl eseri hazırlayan Prof. Dr. Oktay BELLI'yi, ekibini ve esere katkıda bulunan yetkilileri kutluyoruz.

\begin{abstract}
The work of art, "Stone Balbals and Statues in Human Form in Kirghizistan, Arkeoloji ve Sanat Yayınları (Archeology and Art Publisher), Istanbul-2003", prepared by Professor Dr. Oktay BELLI's team as part of Eurasia Archeology Project took place between 04-26 September 2001 in different parts of the Republic of Kirghizistan.

Sorcre! stotuse, ba!hals, kurgans, gravay,ards, mayen!eum complex belong to the ancient Turkish culture and civilisation, most of them are not reported in the literature previously, are identified as a result of surface searches carried out by Eurasia Archeoogy Project Team and presented in this work to the benefit of people who may interested.
\end{abstract}

